\title{
The "Statinth" wonder of the world: a panacea for all illnesses or a bubble about to burst
}

\author{
Nusrat Shafiq ${ }^{1}$, Samir Malhotra*1, Promila Pandhi ${ }^{1}$ and Anil Grover ${ }^{2}$
}

Address: ${ }^{1}$ Department of Pharmacology, Post Graduate Institute of Medical Education and Research, Chandigarh, 160012, India and ${ }^{2}$ Department of Cardiology, Post Graduate Institute of Medical Education and Research, Chandigarh, 160012, India

Email: Nusrat Shafiq - samirmalhotra345@yahoo.com; Samir Malhotra* - samirmalhotra345@yahoo.com;

Promila Pandhi - samirmalhotra345@yahoo.com; Anil Grover - samirmalhotra345@yahoo.com

* Corresponding author

Published: 23 March 2005

Journal of Negative Results in BioMedicine 2005, 4:3 doi:10.1 186/1477-575I-4-3

This article is available from: http://www.jnrbm.com/content/4/I/3

(C) 2005 Shafiq et al; licensee BioMed Central Ltd.

This is an Open Access article distributed under the terms of the Creative Commons Attribution License (http://creativecommons.org/licenses/by/2.0), which permits unrestricted use, distribution, and reproduction in any medium, provided the original work is properly cited.
Received: 07 February 2005

Accepted: 23 March 2005

\begin{abstract}
After the introduction of statins in the market as effective lipid lowering agents, they were shown to have effects other than lipid lowering. These actions were collectively referred to as 'pleiotropic actions of statins.' Pleiotropism of statins formed the basis for evaluating statins for several indications other than lipid lowering. Evidence both in favour and against is available for several of these indications. The current review attempts to critically summarise the available data for each of these indications.
\end{abstract}

Recently while browsing through the internet, we came across a webpage [1] that reads as follows: "Statin drugs should probably be in the water, like fluoride. These cholesterol fighting wonders have been proven to prevent heart attacks..... with only rare side effects.............. The hitch is that statins cost more than fluoride. A lot more. The drug industry's statin sales surpassed US \$15 billion last year. The cholesterol fighting power of products like Pfizer's Lipitor and Merck's Zocor have won them the title 'Superstatins' and made them supersellers. Lipitor brought in US $\$ 9.2$ billion in 2003 sales for Pfizer, making it the biggest prescription drug in the world."

In 2001, we reviewed the statin literature for Medscape and were able to enlist about seven indications[2], the major one being dyslipidemia with associated coronary disease (CAD). The 1993 National Cholesterol Education Programme (NCEP) guidelines [3] were cautiously optimistic about the future of statins but subsequent publication of 3 landmark trials [4-6], greatly tilted the balance in their favour and since then they haven't looked back: a large number of trials and guidelines added new intensity to cholesterol lowering with the low density lipoprotein cholesterol (LDL-C) targets going for a free fall $(<70 \mathrm{mg} /$ $\mathrm{dl}$ in some situations) [7-12]. Although this approach of more intense lipid lowering has met with considerable criticism, this is not the topic of this review. We intend to discuss the other novel, upcoming uses of statins.

In contrast to the post-hoc analysis of the Scandinavian Simvastatin Survival Study (4S) [4] in which the benefit provided was related to the magnitude of change in the LDL-C levels, some other studies have shown benefits that could not be accounted for by reduction in LDL-C alone [13-16]. A large number of studies showing pleiotropism of statins followed and diverse mechanisms were then proposed to explain this pleiotropism including antiinflammatory, immunomodulating, and effects on apoptosis [17-22], making them potentially suitable candidates for the treatment of a wide variety of pathological conditions in many of which they are already being investigated. 
This article attempts to summarize the available evidence for the proposed (other than lipid lowering) indications of statins.

\section{Arrhythmias}

Several actions of lipid lowering therapy like reduction in myocardial ischemia, improvement of autonomic function, changes in protein channel function and inhibition of cardiac remodelling make them prospective agents for the treatment of arrhythmias[22,23]. Chronically administered pravastatin was shown to reduce the incidence of ischemia-induced ventricular tachyarrhythmias in experimental models [24,25]. Early use of pravastatin in patients with acute myocardial infarction (MI) reduced the incidence of in-hospital ventricular arrhythmias irrespective of the lipid levels [26]. The Anti-arrhythmia Versus Implantable Defibrillators (AVID) Study showed that lipid lowering therapy decreased the recurrence rate of ventricular arrhythmias in patients implanted cardioverter-defibrillator [27].

Statins have also been shown to have a role in the treatment of atrial arrhythmias. Inflammatory changes have been shown in atrial biopsy specimens of patients with lone atrial fibrillation (AF) [28]. Furthermore, serum levels of C-reactive protein (CRP), a sensitive marker of systemic inflammation, were increased in patients with AF. Not only that, CRP levels were higher in patients with persistent rather than paroxysmal $\mathrm{AF}$, and persistent $\mathrm{AF}$ is less likely to spontaneously revert to sinus rhythm $[29,30]$. These studies suggested that inflammation may induce, provoke and promote the persistence of AF. Statins may be potent anti-inflammatory agents [31] and have also been shown to reduce CRP levels [32].

Not surprisingly, statins were subsequently shown to prevent $\mathrm{AF}$ recurrence in patients with lone $\mathrm{AF}$ after successful cardioversion [33] and in patients with CAD[34]. Both these studies were retrospective. However, it is well known that results obtained in retropsective studies may not be replicated in clinical trials [35]. Accordingly, in an open, controlled multicenter study, pravastatin did not reduce the recurrence rate of $\mathrm{AF}$ after electroversion[36]. Moreover, there has been an isolated case report of AF due to simvastatin[37], which further limits their role in the management of arrhythmias.

The evidence available for the beneficial role of statins is largely from observational and experimental studies which is clearly insufficient to recommend them as primary or even adjunctive antiarrhythmic agents. Moreover, their role in prevention as well as treatment of arrhythmias remains to be clearly defined.

\section{Heart failure}

Initial experimental evidence indicated towards both potential harm and benefit of statins in heart failure. Statins modulate a variety of inflammatory and immune responses [38-40]. In animal models of heart failure, statins moderate abnormal collagen and $\beta$-myosin expression, attenuate increased matrix metalloproteinase activity, improve ventricular remodelling and systolic function, normalize sympathetic responses and improve survival [41-43] Given the relation of systemic inflammation to morbidity and mortality in heart failure patients, it was hypothesised that statins may benefit patients with heart failure separately from or in addition to effects on cholesterol and coronary disease[44].

In a report of 551 patients with systolic heart failure, statin use was associated with improved survival in patients with ischemic and non-ischemic heart failure[45]. After risk adjustment for age, gender, CAD, cholesterol, diabetes, medication, hemoglobin, creatinine and NYHA functional class, statin therapy remained an independent predictor of improved survival. Furthermore, in a randomised trial in 63 patients with heart failure, statin use improved NYHA class and ejection fraction when compared with placebo [46]. Also, statin therapy reduced new onset heart failure in the 4S Study [47], but this may have been related to effects on recurrent myocardial infarction. Using data from the Prospective Randomised Amlodipine Survival Evaluation (PRAISE) trial, association of statin therapy with total mortality among 1,153 patients with severe heart failure was evaluated [48]. Statin therapy was associated with a $62 \%$ lower risk of death. However, only $12 \%$ patients were receiving statin therapy. Moreover, the study results cannot be generalised as these patients participated in a clinical trial at a time when $\beta$ blockers and spironolactone were not commonly used in severe heart failure.

There also is some evidence to the contrary; lower serum cholesterol predicts worse outcomes in heart failure [49], raising concerns regarding use of lipid lowering agents. Statins also reduce ubiquinone (enzyme Q-10) [50], which may adversely affect mitochondrial and cardiac muscle function.

Therefore, in lieu of conflicting experimental and clinical data, the routine use of statins in congestive heart failure will be premature.

\section{Cardiomyopathy (CMP)}

In initial experimental studies, simvastatin was shown to induce regression of cardiac hypertrophy and fibrosis and improve cardiac function in a transgenic rabbit model of human hypertrophic CMP [51]. Based on the knowledge that statins improve endothelial function [39] and 
suppress systemic inflammation [31], it was hypothesized that statins may improve cardiac function in patients with nonischemic dilated CMP [46]. Fourteen weeks of treatment with simvastatin was shown to improve left ventricular ejection fraction, reduce plasma concentration of tumour necrosis factor-alpha, and brain natriuretic factor in patients with idiopathic dilated CMP[52]. The effect on patient outcomes was however not evaluated.

Again as in case of heart failure, although some evidence is available for the beneficial effect of statins in CMP, evidence to the contrary is also available. Lovastatin has been shown to significantly increase mortality in hamsters with cardiomyopathic heart due to reduction in ubiquinone supply[53]. Statins have been shown to decrease coenzyme Q levels in humans [54] and this coenzyme is indispensable for cardiac functions [55]. In wake of such conflicting evidence, their use in ishemic/nonishemic CMP cannot be advocated.

\section{Diabetic dyslipidemia}

In addition to microvascular complications, patients with type 2 diabetes are at an increased risk of developing CAD [56] Over a 7-year period, in patients with no history of $\mathrm{CAD}$, the incidence of first MI was over five times greater for patients with diabetes compared with non-diabetic controls [57]. Diabetes is now considered to be a cardiovascular disease and all diabetics, irrespective of history of $\mathrm{CAD}$, are considered within the category of secondary CAD prevention. Diabetic dyslipidemia may exist in the absence of raised total serum cholesterol due to an increased proportion of the more atherogenic LDL particles. Moreover, dyslipidemia often exists with a number of other atherogenic co-factors in patients with diabetes (e.g. abdominal obesity and hyperinsulinemia) as a part of metabolic syndrome [58]. The updated Adult Treatment Panel (ATP)-III guidelines have advocated the use of statins for diabetes with or without CAD [12]. LDL lowering treatment when LDL-C is $>100 \mathrm{mg} / \mathrm{dL}$ in diabetices without $\mathrm{CAD}$ and $>70 \mathrm{mg} / \mathrm{dL}$ in diabetics with CAD has been recommended.

Since the appearance of the first report on the efficacy of statins in lowering lipid concentrations in patients with type 2 diabetes [59], clinical trial evidence has accumulated in their support as the primary lipid-lowering drugs for these patients. Subgroup analyses [60] of diabetic patients in the Antihypertensive and Lipid Lowering Treatment to Prevent Heart Attack Trial (ALLHAT-LLT) [9], the MRC/BHF Heart Protection Study (HPS) [15], and the Anglo-Scandinavian Outcomes Trial-Lipid Lowering Arm (ASCOT-LLA) [10] showed variable results of lipid lowering therapy on cardiovascular outcomes in diabetic patients. In ALLHAT-LLT [9] pravastatin did not reduce the incidence of non-fatal MI and CAD deaths in patients with diabetes. In the HPS trial [15] simvastatin significantly reduced the risk of CAD and total cardiovascular events in patients with diabetes, whether they already had CAD or not. In the ASCOT-LLA trial [10] atorvastatin did not reduce the risk of non-fatal MI and CAD death in patients with diabetes and hypertension who had no preexisting CAD. Collaborative Atorvastatin Diabetes Study (CARDS) was carried out to evaluate the efficacy and safety of low-dose atorvastatin treatment in primary prevention of CAD in patients with type 2 diabetes at highrisk of CAD [61]. CARDS Investigators conclude that statins should be used in all patients with type 2 diabetes unless the patient has sufficiently low risk of coronary heart disease.

However, generalization of CARDS results is debatable. For example, the risk of statin therapy might be increased in people older than 75 years of age in patients with chronic renal insufficiency or organ transplantation and in patients with very high triglyceride concentrations who are on fibrates [60]. Moreover, the number needed to treat will be very high in patients in whom the baseline risk is low like those with type 2 diabetes who are younger than 40 years; in premenopausal women; and in those without any CAD risk factors [60].

\section{Development of diabetes}

Lipid lowering therapy with bezafibrate had earlier shown to improve plasma glucose levels and insulin response to $75 \mathrm{~g}$ oral glucose loading associated with hyperinsulinema [62]. An analysis of patients enrolled in the WOSCOPS study had shown a $30 \%$ reduction in the hazard of becoming diabetic [63]. The analysis was done post hoc and the levels of statistical significance was modest ( $\mathrm{p}$ $=0.04$ ). Additionally, by reducing the risk of CAD, the need for $\beta$-blocker use (and perhaps thiazides) was reduced. There is some evidence that $\beta$-blockers $[64,65]$ and thiazides [66] may be associated with an increase in the incidence of diabetes.

Although no effect of pravastatin on glucose levels was shown in another study, [67] the authors proposed that pravastatin might reduce the incidence of diabetes by a reduction in triglyceride (TG) levels. However, even this is unlikely because the effect of pravastatin on TG levels is only modest [68]. A recent case control study from the UK based General Practice Research Database failed to show reduced incidence of development of diabetes [69].

\section{Diabetic maculopathy}

There has been interest in link between serum lipids and retinal exudates for 40 years [70]. A number of cross-sectional studies suggest that serum lipids may have a causative role in the formation of macular exudates [71-74]. A cross-sectional study of Age-related Macular Degeneration 
(AMD) suggests that statin therapy does have a protective role against the development of macular degeneration [75].

Few studies have evaluated statins in diabetic retinopathy $[76,77]$. In one of these, an improvement in hard exudates was noted in all patients on statins [76]. In another study, simvastatin was shown to improve fluoroscein angiographic picture and led to maintenance of visual acuity in all patients [78].

These data, though important, do not permit us to draw a final conclusion as these studies were inadequately powered.

\section{Claudication}

Claudication occurs when blood flow to the extremity fails to meet the metabolic demands of the skeletal muscle during exercise. It was hypothesised that statins, by improving endothelium dependent vasodilation at the arteriolar and capillary level [79], by their proangiogenic response independent of cholesterol reduction [80], and by inhibition of MMP-9 secretion by peripheral monocytes [81], could be beneficial in reducing claudication in patients with peripheral arterial occlusive disease (PAOD). Studies with lipid modifying therapies have demonstrated desirable effects in patients with PAOD $[82,83]$. A post-hoc analysis of the $4 \mathrm{~S}$ data showed that new or worsening claudication was reduced in the group of patients receiving statins [84]. High-dose, short-term therapy with simvastatin has been shown to improve walking performance, ankle-brachial pressure indices, and symptoms of claudication in hypercholesterolemic patients with PAOD [85]. One-year treatment with atorvastatin improved pain free walking time and participation in physical activity in patients with intermittent claudication [86]. However, maximal walking time did not change significantly. Similar benefit was shown with simvastatin on treadmill exercise time until the onset of intermittent claudication [87].

Despite the evidence from these studies suggesting benefit, well-designed long-term studies assessing primary and secondary prevention of PAOD with defined endpoints such as amputation or number of vascular events are required.

\section{Multiple sclerosis (MS)}

In an experimental model of encephalomyelitis, lovastatin treatment was shown to block disease progression and induction of inflammatory cytokines [88]. Lovastatin treatment also attenuated the transmigration of mononuclear cells by downregulating the expression of leukocyte function antigen-1 (LFA-1), a ligand for intercellular adhesion molecule (ICAM), in endothelial-leukocyte interaction [88] and mononuclear cell infiltration into the CNS has been implicated in MS [89]. Atorvastatin was shown to promote Th2 bias and reverse paralysis in a CD4(+)Th1-mediated experimental model of MS [90].

Therefore, statins were recognised as potential agents for future pharmacotherapy of MS [91]. In the first clinical trial of statins in MS, $80 \mathrm{mg}$ oral simvastatin for 6 months significantly reduced the number and volume of gadolinium enhancing lesions [92]. However, immunological expression of surface markers on leukocyte cells or inflammatory cytokine profile showed no changes. Moreover, it was an uncontrolled, open label, small study with a baseline versus treatment comparison. Therefore, its results must be interpreted with caution. For instance, it is possible that reduction in the disease severity as measured with MRI could be due to regression to the mean. Moreover, since patients were included on the basis of the presence of gadolinium enhancement, this might have led to selection of patients with active disease who may subsequently have shown spontaneous reduction in disease activity anyhow. Additional factors like steroid use and unblinded assessment of MRI scans may have influenced the results. The exploratory immunological data in this study were also not found to be supportive.

Due to the paucity of evidence from adequately powered good quality clinical trials demonstrating the benefits of statins, any conclusive statement would be rather premature. Several trials are currently underway to address this question and we are also conducting a Double-blind, Randomised Evaluation of Atorvastatin in Multiple Sclerosis (DREAMS) trial in our institution.

\section{Stroke}

Although cholesterol lowering is well known to decrease the risk of $\mathrm{CAD}$, its association with decreased risk of stroke was demonstrated later [93]. Meta-analyses done recently have shown statin use to be associated with reduced risk of stroke by 12 to $24 \%[94,95]$.

Analysis of data from nine cohort studies showed a 15\% decrease in thromboembolic stroke but a $19 \%$ increase in hemorrhagic stroke for a $1.0 \mathrm{mmol} / \mathrm{l}$ decrease in LDL concentration. The risk in those without a known cardiovascular risk factor was shown to be the same $(6 \%)$ in clinical trials as that seen in cohort studies [91]. Though the overall risk of non-fatal strokes was reduced, the risk of fatal strokes was not [96]. Also, these results were obtained from studies which had stroke as their secondary endpoint. Moreover, in most of the included studies, incidence of stroke was very low, especially for primary prevention, reducing the power of comparison. 


\section{Alzheimer's disease (AD)}

Addition of lovastatin to human HEK cells transfected with the amyloid precursor protein (APP) was shown to reduce intracellular cholesterol/protein ratios by $50 \%$, and to inhibit cleavage of APP by beta-secretase [97]. Non-demented individuals with heart disease have increased prevalence of AD-like beta-amyloid deposits in the neuropil and within neurons [98]. In a cohort of patients taking lovastatin and pravastatin (but not simvastatin), a lower prevalence of diagnosed probable AD was noted [99]. A case control study has also shown a lower risk of dementia among users of statins [100].

However, in a review done by the Cochrane Group, it was pointed out that no evidence in the form of controlled clinical trials was available to recommend the use of statins in $\mathrm{AD}$ [101]. In a subsequent randomised, placebo controlled, double-blind trial, 26-week treatment with 80 mg simvastatin did not show any significant alteration in the cerebrospinal fluid levels of A-beta 40 and A-beta 42 [102]. Though the body of evidence for the beneficial effect of statins for AD is growing, due to the paucity of randomised controlled trials, no conclusions can yet be drawn [103].

Moreover, excessive lipid lowering may be detrimental as too little cholesterol in neural membranes has been shown to increase the vulnerability of neural membranes to dysfunction [104]. Low serum cholesterol concentrations have been shown to be associated with cognitive decline in prospective studies of aging American twins [105] and elderly Finns [106].

\section{Depression}

Two observational studies showed that long-term statin use is associated with a reduced risk of depression in patients with CAD $[107,108]$. After an average follow up of 4 years, comparison of psychometric scores between users and nonusers of statins showed that statin use was associated with lower risk of abnormal scores for depression, anxiety and hostility [107]. Authors have attributed the findings to a possible direct effect of statins on psychological well being. Similar reduced risk of depression was noted with statins in patients with hyperlipidemia [108]. A more plausible possibility of reduced risk of depression due to an improvement in the overall quality of life was suggested in this study.

On the other hand, lowering of serum cholesterol may be associated with an increased incidence of depression and suicides [109-113]. To sort of neutralize the evidence, some randomised, placebo controlled trials of statins have shown that depression was neither more nor less common among those taking active treatment [114-116].

\section{Rheumatoid arthritis (RA)}

Statins were shown to inhibit LFA-1, which is known to play an important role in the pathophysiology of inflammatory and autoimmune diseases [117]. Statins also led to significant suppression of collagen-specific Th 1 humoral and cellular immune responses, reduction of anti-CD3/anti-CD28 proliferation and IFN-gamma release from mononuclear cells derived from peripheral blood and synovial fluid [118]. Based on these findings, a putative role for statins in RA was suggested.

A preliminary study done in 15 patients with RA who were receiving methotrexate as a single disease modifying agent with no satisfactory responses, showed improvement after eight weeks of treatment with $40 \mathrm{mg}$ simvastatin [119]. Recently, in a randomized placebo controlled trial [120], atorvastatin $40 \mathrm{mg}$ was shown to significantly improve disease activity score after 6 months of therapy although the effects were modest. The use of disease modifying antirheumatic drugs was rather heterogeneous among the treatment groups in this study, with more patients receiving methotrexate in the atorvastatin group. Other limitations were a small study group and a direct effect of statins on hepatic CRP synthesis, which could exaggerate the impression of disease modification.

\section{Osteoporosis}

The biologic effects of statins on bone metabolism have been reported in literature [121]. Statins were shown to be potent stimulators of bone formation in vitro. Statins were shown to stimulate the bone morphogenic protein-2 (BMP-2) promoter in an immortalized osteoblast cell line [121]. BMP-2 is known to enhance osteoblast differentiation [122]. Further supporting evidence for its beneficial role came from osteoporosis observational studies [123126]. However, in these studies, no adjustment for weight was made and part of the protective effect of statins could be because of reduction in weight.

By contrast, the Women's Health Initiative Observation Study found no relationship between statins and hip/ wrist/arm/non-spine fracture rates after adjusting for weight and other potential confounders [127]. Lack of benefit of statins in reducing hip and non-spine fracture was also reported in a case control study from the General Practice Research Database [128]. In the first placebo-controlled trial specifically designed to assess bone turnover, statin treatment did not show any difference in rates of bone formation [129]. Other uncontrolled studies have been conflicting; both increased [130] and decreased $[131,132]$ rates of bone formation have been reported. In spate of high optimism, it has been suggested that increasing the bioavailability of statins to the bone may lead to better results [133]. As of now, keeping in mind lack of a consistent response with statins in various studies, it will 
be inappropriate to conclude that statins have a meaningful benefit for patients with osteoporosis.

\section{Cancer}

Similar to most of the above mentioned indications, the action of statins in cancer has been bi-fold with arguments and evidence both in favour and against having been published.

It was suggested, nearly a decade ago, that cholesterol inhibition could inhibit tumour cell growth and possibly prevent carcinogenesis [134]. Recently, statin use was shown to be associated with a reduced risk of breast [135] and colorectal [136] carcinoma. However, these findings need confirmation as they were based on a small number of events. Statin use has been associated with a $20 \%$ reduction in colon cancer, if used for more than 4 years and if more than 1350 defined daily doses were taken [136].

Evidence to the contrary has also grown simultaneously. Epidemiological studies in the early 1990s had shown a rise in non-cardiovascular mortality, particularly cancer deaths in people with low cholesterol concentrations [137]. Similar conclusions have been drawn from results of early trials of cholesterol lowering [138]. Some researchers have shown that lipid-lowering drugs, including statins, increase the occurrence of several types of cancer in rodents [139]. In the CARE trial [6], incidence of female breast cancer and in the PROSPER trial [8] in elderly, incidence of all cancers increased in patients given pravastatin.

With such conflicting evidence available there is a need for exercising cautious scepticism for a potential beneficial role of statins for cancers.

\section{Acquired Immune Deficiency Syndrome}

Hyperlipidemia induced by antiretroviral treatment is observed frequently and can cause an increase in cardiovascular risk in HIV patients [139]. Moreover, HIV infection itself induces pro-atherogenic lipid changes, which may lead to an increased cardiovascular risk but are partly reversed by antiretroviral regimens [140]. Statins, given to patients with HIV infection and hyperlipidemia, effectively reduced total cholesterol $(27 \%)$ and triglycerides (15\%) [141]. In the first double-blind, placebo-controlled study of the effects of statin therapy on lipids, lipoprotein subfractions, and endothelial function in HIV patients taking protease inhibitors, pravastatin reduced concentrations of atherogenic lipoproteins [142]. Similar beneficial effects of statins were shown in a cohort of 245 patients [143]. However, in all these studies the decrease in total cholesterol, LDL and triglycerides was only modest, and a significant number of patients did not achieve their NCEP goals. Moreover, the risk of rhabdomyolysis with concomitant use of statins in patients receiving highly active antiretroviral therapy needs to be carefully evaluated in future studies.

Statins have been shown to have a direct effect on HIV infection itself [144,145]. In in vitro studies, 9 days after viral loading, lovastatin inhibited both sterol synthesis and viral multiplication in Human H9 lymphocytic cell line [144]. Rho-guanosine triphosphatase (GTPase) activity is required for HIV infectivity into the cells [145]. Statins block Rho-A activation induced by HIV-1 binding to target cells and also inhibited entry of HIV-1 pseudotyped viruses. These data are only experimental and considerable work will need to be done before any speculations for anti-retroviral potentials of statins are made.

\section{Other indications}

Some of the other uses for which statins are being evaluated are drug-induced dyslipidemia following transplantation [146,147], for causing immunosuppression in patients undergoing organ transplantation [148], promotion of fracture healing in vascularised bone allograft [149], sickle cell anemia [150,151], idiopathic pulmonary fibrosis [152,153], sensorimotor recovery after experimental intra-cerebral haemorrhage [154], sepsis [155157], and glomerulonephritis [158]. However, only limited, preliminary data are available to support routine use of statins in most of these indications and no recommendations can be made at present.

\section{Safety issues}

One cannot ignore the safety concerns with statin use; besides the well known side effects of myopathy, procarcinogenesis potential $[159,160]$, nerve damage $[161,162]$, short temper [163], cognitive decline [164], memory loss [165], teratogenic potential $[166,167]$, and more recently loss of libido [168] are some of the other concerns.

\section{The rise, plateau and fall (?) of statins}

There is no doubt that statins have become one of the most commonly utilized drugs in cardiac patients not only in developed [169] but also in developing nations [170]. It is also obvious that their use will be intensively promoted in many non-cardiac conditions discussed above although the tremendous promise seen in some experimental and initial clinical studies failed to be sustained in clinical trials or if it did the effect was only modest. For others the initial conflicting results continue to exist.

Recent years have shown a kind of contagiousness being demonstrated in research. Foremost among these have been the case of COX-2 inhibitors. After the discovery of COX-2 isoenzyme, almost every pathophysiological 


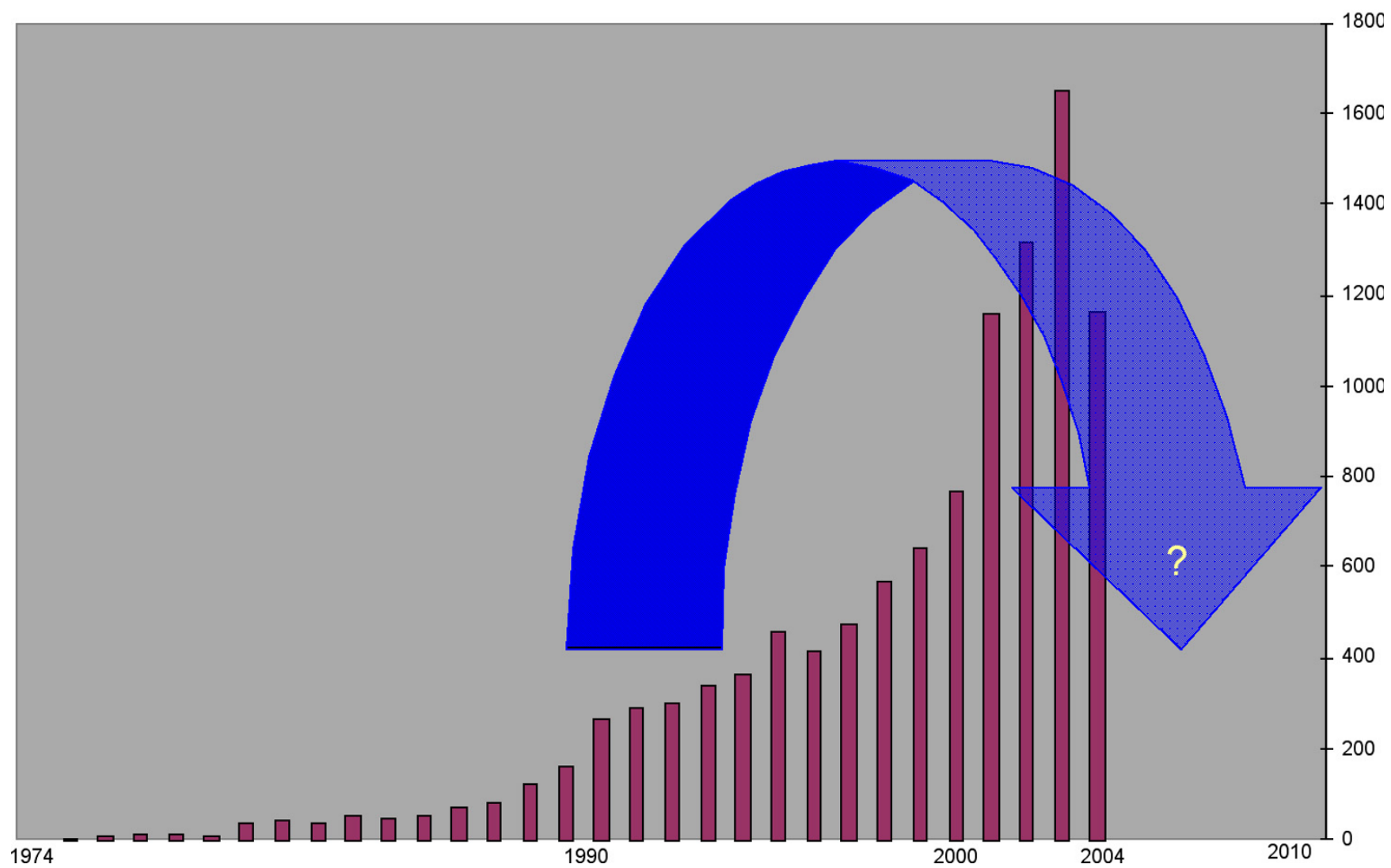

Figure I

Number of statin publications in each year from 1974 to 2004. The numbers depict the citations obtained from Pubmed on entering the MeSH term 'Statins'

process showed involvement of COX-2 [171,172]. Selective inhibition of COX-2 was thought to be the answer to a number of problems in therapeutics. A large number of studies giving evidence to the contrary or addressing adverse effects of COX-2 inhibitors got overshadowed (or were suppressed) in the hype created over COX-2 inhibitors $[173,174]$. Rofecoxib and some other selective COX2 inhibitors are being withdrawn for their adverse effect profiles as their discoverer companies gear up for payments of compensation claims made by sufferers. Many other molecules have suffered similar fate and we hypothesized that statin research may also be on decline.

To test this hypothesis we searched Medline using the MeSH term "statins", "statins AND cancer (as well as other indications one by one)" for overall and yearwise extraction of citations. A total of approximately 11,000 citations were found out of which about $50 \%$ have appeared in only the past 4 years (since our last review [2]). An analy- sis of yearly trends showed some interesting details. The first study on statins was reported in 1975 [175]. Subsequently, there was a steady increase in the publications until pleiotropism of statins was suggested in the mid-90s [176] and since then (especially since 2000), a steep rise in publications for various indications with a peak around 2002-2003 can be noticed. It is interesting to note that a trend towards a decline in the number of these studies can already be seen for statins in general (Fig 1) and in many indications specifically (Fig 2). This declining trend is probably due to failure to establish any definite benefit in majority of the indications for which their use was proposed.

Therefore, our hypothesis which appeared quite implausible initially may not have been altogether wide of the mark. Consequently, it remains to be seen whether statins can withstand the test of time or will sink into oblivion like many of the other molecules. 
Fig 2. Declining trend in publications for some of the indications of

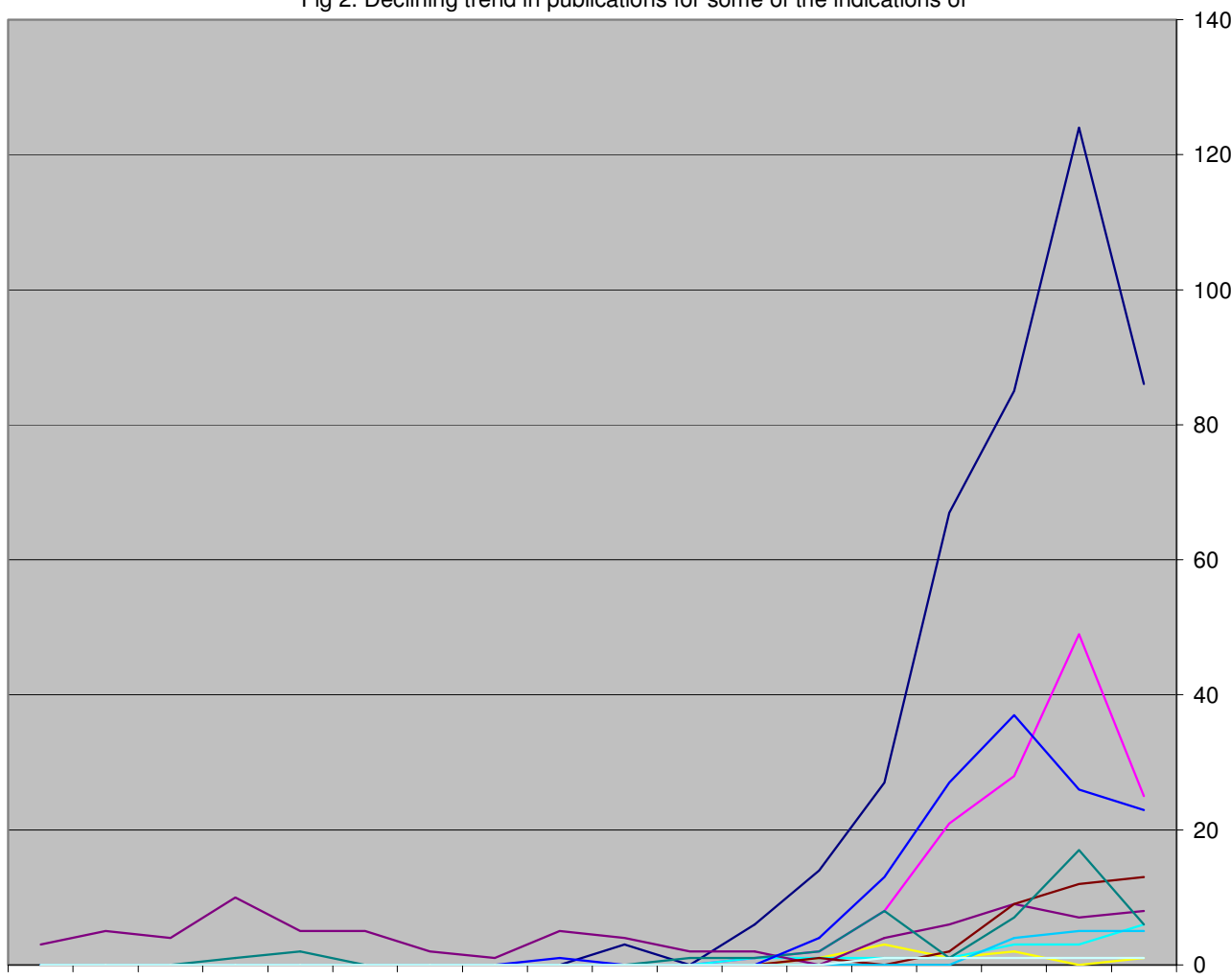

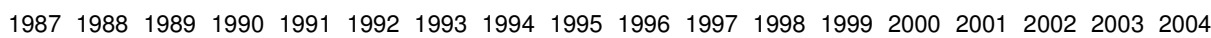
Diabetic Maculopathy

Figure 2

The trend in the number of published research articles in Pubmed, categorized according to the various pathological conditions discussed in the text.

\section{Conclusion}

If we take an overview of the evidence available for each of the above indications of statins we notice that it is rather weak even for the indications in which there are controlled trials available. Moreover, these trials are either inadequately powered or have measured only soft endpoints or have been of short duration to be conclusive. And lastly, a considerable number of contradictory studies make their utility in most of these diverse conditions doubtful.

\section{References}

I. Bill A: The state of statins. [http://www.smartmoney.com/ bar rons/index.cfm? Story $=200406$ I4]. June 14 2004. Accessed 9 Sep 2004

2. Malhotra S, Grover A, Munjal G: Staturs of statins. Indications, utilization and unanswered questions. [http://www.med scape.com/Medscape/pharmacology/journal/200IV03.no3/ mp0502.malh/mp0502].
3. Summary of the second report of the National Cholesterol Education Program Expert Panel. (NCEP) Expert Panel on Detection, Evaluation, and Treatment of High Blood Cholesterol in Adult (Adult Treatment Panel II). J Am Med Assoc 1993, 269:2486-2497.

4. Scandinavian Simvastatin Survival Study Group: Randomized trial of cholesterol lowering in 4444 patients with coronary heart disease. The Scandinavian Simvastatin Survival Study (4S). Lancet 1994, 334:1383-1389.

5. Shepherd J, Cobbe SM, Ford I, for the West of Scotland Coronary Prevention Study Group, et al.: Prevention of coronary heart disease with pravastatin in men with hypercholesterolemia. $N$ Engl J Med 1995, 333: I 30I-1307.

6. Socks FM, Pfeiffer MA, Moye LA, et al.: The effect of pravastatin on coronary events after myocardial infarction in patients with average cholesterol levels. Cholesterol and Recurrent Events Trial Investigators. N Engl J Med 1996, 335: I00 I-1009.

7. Heart Protection Study Collaborative Group: MRC/BHF Heart protection study of cholesterol lowering with simvastatin in $\mathbf{2 0 , 5 3 6}$ high-risk individuals, a randomized placebo-controlled trial. Lancet 2002, 360:7-22.

8. Shepheerd J, Blauw GJ, Murphy MB, PROSPER Study group, et al:: Pravastatin in elderly individuals at risk of vascular disease (PROSPER): a randomized controlled trial: Prospective 
Study of Pravastatin in the Elderly at Risk. Lancet 2002, 360:1623-1630

9. ALLHAT Officers and Coordinators for the ALLHA Collaborative Research Group: The antihypertensive and lipid-lowering treatment to prevent Heart Attack Trial. Major outcomes in moderately hypercholesterolemic hypertesnsive patients randomized to pravastatin vs usual care. The Antihypertensive and Lipid Lowereing Treatment to Prevent the Heart Attack Trial(ALLHAT-LLT). JAMA 2002, 288:2998-3007.

10. Sever PS, Dahlof B, Poulter NR, et al.: Prevention of coronary and stroke events with atoravastatin in hypertensive patiens who have average or lower than average cholesterol concentrations in the the Anglo-Scandinavian Cardiac Outcomes Trial- Lipid Lowering Arm (ASCOT-LLA): a multicenter randomized control trial. Lancet 2003, 36 I: | | 49- I I 58.

II. Cannon SP, Braunwald E, Mc Cabe H, et al.: Pravastatin or Atorvastatin Evaluation and Infection Therapy-Thrombolysis in Myocardial Infarction-22 Investigators. Intensive versus moderate lipid lowering with statins after acute coronary syndromes. N Engl J Med 2004, 350: | 495- I 504.

12. Grundy SM, Cleeman JI, Merz CN, for the Coordinating Committee of the National Cholesterol Education Program, et al.: Implications of Recent Clinical trials for the National Cholesterol Education Program Adult Treatment Panel III guidelines. Circulation 2004, I 1 0:227-239.

13. Schwarz GG, Olsson AG, Ezekowitz MD, for the Myocardial Ischemia Reduction with Aggressive Cholesterol Lowering (MIRACL) Study Investigators, et al.: Effects of atorvastatin on early recurrent ischaemic events in acute coronary syndromes. The MIRACL study: a randomized controlled trial. JAMA 200I, 285: $1711-1718$.

14. Simes RJ, Marscher IC, Hunt D, on behalf of the LIPID study investigators, et al:: Relationship between lipid levels and clinical outcomes in the Long-term Intervention with Pravastatin in Ischemia Disease (LIPID) Trial. To what extent is the reduction in coronary events with pravastatin explained by onstudy lipid levels? Circulation 2002, 105: I 62-I I69.

15. Heart Protection Study Collaboration Group: MRC/BHF Heart Protection Study of cholesterol lowering with simvastatin in 20,536 high risk individuals: a randomized placebo controlled trial. Lancet 2002, 360:7-22.

16. Buchwald $\mathrm{H}$, Campos CT, Boen JR, for the POSCH Group, et al:: Disease-free intervals after Partial ideal bypass in patients with coronary heart disease and hypercholesterolemia: report from the program on the Surgical Control of Hyperlipidemias (POSCH). J Am Coll Cardiol 1990, 26:35I-357.

17. La Rosa JC: Pleiotropic effects of statins and their clinical significance. Am J Cardiol 200I, 88:29I-293.

18. Gotto AM Jr, Farmer JA: Pleiotropic effects of statins; do they matter? Curr Opin Lipidol 200I, I 2:39|-394.

19. Shonebeck U, Libby P: inflammation, immunity and HMG-CoA reuctase inhibitors. Statins as anti-inflammatory agents. Circulation 2004, 109:18-26.

20. Halcox JPJ, Deanfield JE: Beyond the laboratory: Clinical implications for statin pleiotropy. Circulation 2004, 109:42-48.

21. Waldman A, Kritharides $L$ : The pleiotropic effects of HMG-CoA reductase inhibitors. Their role in osteoporosis and dementia. Drugs 2003, 63:139-152.

22. Comparato C, Altana C, Bellosta S, et al:: Clinically relevant pleiotropic effects of statins: drug properties or effects of profound cholesterol reduction? Nutr Metab Cardovasc Dis 200I, II:328-343.

23. Henry PD, Pacific A: Altering molecular mechanisms to prevent sudden arrhythmic death. Lancet 1998, 35 I: I 276- I278.

24. Lee TM, Chou TF, Tsai CH: Effect of pravastatin on cardiomyocyte hypertrophy and ventricular vulnerability in normolipidemic rats after myocardial infarction. I Mol Cell Cardiol 2003 35: $1449-1459$

25. Chen J, Nagasawa Y, Zhu BM, et al.: Pravastatin prevents arrhythmias induced by coronary artery ischemia/ reperfusion in anaesthetized normocholesterolemic rats. J Pharmacol Sci 2003, 93:87-94.

26. Kayikcioglu M, Can L, Everengul H, et al.: The effect of statin therapy on ventricular late potentials in acute myocardial infarction. Int J Cardiol 2003, 90:63-72.
27. Mitchell LB, Powell JL, Gillis AM, et al.: Are lipid lowering drugs also antiarrhytmic drugs? An analysis of the Anti-arrhythmic Versus Implantable Defibrillator Trial (AVID Trial). J Am Coll Cardiol 2003, 42:8I-87.

28. Frustaci $A$, Chimenti $C$, Bellocci $F$, et al.: Histological substrate of atrial fibrillation-biopsies in patients with lone atrial fibrillation. Circulation 1997, 96: I 80- I I84.

29. Chung MK, Martin DO, Sprecher D, Wazni, et al.: C-reactive protein elevation in patients with atrial arrhythmias: inflammatory mechanisms and persistence of atrial fibrillation. Circulation 200I, 104:2886-2891.

30. Dernellis J, Panaretou M: C-reactive protein and paroxysmal atrial fibrillation. Evidence of the implication of an inflammatory process in paroxysmal atrial fibrillation. Acta Cardiol 200I, 56:375-380.

31. Lefer DJ: Statins as potent anti-inflammatory drugs. Circulation 2002, 106:204|-2042

32. Albert MA, Danielson E, Rifai N, et al.: Effect of statin therapy on C-reactive protein levels: the Pravastatin Inflammation/CRP Evaluation (PRINCE): a randomized trial and cohort study. JAMA 200I, 286:64-70.

33. Siu CW, Lau CP, Tse HF: Prevention of atrial fibrillation recurrence by statin therapy in patients with lone atrial fibrillation after successful cardioversion. Am J Cardiol 2003, 92: I343-1345.

34. Young-Xu $Y$, Jabbour $S$, Goldberg $R$, et al: Usefulness of statin drugs in protecting against atrial fibrillation in patients with coronary artery disease. Am J Cardiol 2003, 92:1379-I383.

35. Malhotra S, Kondal A, Shafiq N, et al.: Comparison of observational and controlled trials of heparin in ulcerative colitis. Int J Clin Pharmacol Ther 2004 in press.

36. Tveit A, Grundtvig M, Gundersen T, et al.: Analysis of pravastatin to prevent recurrence of atrial fibrillation after electrical cardioversion. Am J Cardiol 2004, 93:780-782.

37. Akahane $\mathrm{T}$, Mizushige $\mathrm{K}$, Nishio $\mathrm{H}$, et al: Atrial fibrillation induced by simvastatin treatment in a 61 -year old man. Heart Vessel 2003, 18:157-159.

38. Ridker PM, Rifai N, Lowenthal SP: Rapid reduction in C-reactive protein with carivastatin among $\mathbf{7 8 5}$ patients with primary hypercholesterolemia. Circulation 2001, 103:1 I9I-1 I93.

39. Holm T, Andreassen AK, Ueland T, et al.: Effect of pravastatin on plasma markers of inflammation and peripheral endothelial function in male heart transplant recipients. Am J Cardiol 200 I, 87:815-818.

40. Palinski W, Tsimikas S: Immunomodulatory effects of statins: mechanisms and potential impact on arteriosclerosis. I Am Soc Nephrol 2002, 13:1673-168I.

4I. Bauersachs J, Galuppo P, Fraccarollo D, et al:: Improvement of left ventricular remodelling and functioning by hydroxymethylglutaryl coenzyme reductase inhibition with cerivastatin in rats. Circulation 2001, 104:982-985.

42. Hayashidani $\mathrm{S}$, Tsutsui $\mathrm{H}$, Shiomi $\mathrm{T}$, et al:: Flurvastatin, a 3 hydroxyl-3-methylglutaryl coenzyme a reductase inhibitor, attenuates left ventricular remodelling and failure after experimental myocardial infarction. Circulation 2002, 105:868-873.

43. Pliquett RU, Cormsti KG, Peuler JD, et al: Simvastatin normalizes autonomic neural control in experimental heart failure. Circulation 2003, 107:2493-2498.

44. Kapadia S, Dibbs Z, Kurrelmeyer K, et al.: The role of cytokines in the failing heart. Cardiol Clin 1998, 16:645-656.

45. Horwich TB, Maclellan WR, Fonarow GC: Statin therapy is associated with improved survival in ischaemic and nonischaemic heart failure. J Am Coll Cardiol 2004, 43:642-648.

46. Node K, Fujita M, Kitakaze M, Hori M, Lia JK: Short-term statin therapy improves cardiac functions and symptoms in patients with idiopathic dilated cardiomyopathy. Circulation 2003, 108:839-843.

47. Kjekshus J, Pedersen TR, Olsson AG, et al.: The effects of Simvastatin on the incidence of heart failure in patients with coronary heart disease. I Card Fail 1997, 3:249-254.

48. Mozaffarian D, Nye R, Levy WC: Statin therapy is associated with lower mortality among patients with severe heart failure. Am I Cardiol 2004, 93: I I 24-1 I 29.

49. Rauchhaus M, Coats AJ, Anker SD: The endotoxin-lipoprotein hypothesis. Lancet 2000, 356:930-933. 
50. De Pinieux G, Chariot P, Ammi-Said M, et al.: Lipid-lowering drugs and mitochondrial function; effects of HMG-CoA reductase inhibitors on serum ubiquinone and blood lactate/ pyruvate ratio. Br J Clin Pharmacol 1996, 42:333-337.

5I. Patel R, Negueh SF, Tsyboeuleva N, et al: Simvastatin induces regression of cardiach hypertrophy and fibrosis and improves cardiac function in a transgenic rabbit model of human hypertrophic cardiomyopathy. Circulation 2001, 104:317-324.

52. Gheorghiade $M$, Klein L, Stone NJ, et al.: Improvement in the function of hibernating myocardium in patients with heart failure due to coronary artery disease receiving high dose simvastatin. Ital Heart J 2004, 5: 1650-I662.

53. Belichard P, Prunceu D, Zhiri A: Effect of long term treatment with lovastatin or fenofitrate on hepatic and cardiac ubiquone levels in cardiomyopathic hamster. Biochem Biophys Acta 1993, I169:98-102.

54. Folkers K, Langsjoen $\mathrm{P}$, Willis R, et al.: Lovastatin decreases coenzyme $\mathbf{Q}$ levels in humans. Proc Natl Acad Sci USA 1999, 87:8931-8934.

55. Hargreaves IP: Ubiquinone; cholesterol's reclusive cousin. Ann Clin Biochem 2003, 40:207-218.

56. Haffner SM, Lehto S, Ronnemaa T, et al.: Mortality from coronary heart disease in subjects with type 2 diabetics and non-diabetic subjects. N Engl J Med 1998, 339:229-234.

57. Syvanne M, Taskinen MR: Lipids and lipoproteins as coronary risk factors in non-insulin dependent diabetes mellitus. Lancet 1997, 350(Suppl I):20-23.

58. Reaven GM: Pathophysiology of insulin resitance in human disease. Physiol Rev 1995, 75:473-486.

59. Garg A, Grundy SM: Lovastatin for lowering cholesterol levels in non-insulin dependent diabetes mellitus. N Engl J Med 1988 318:8I-86

60. Garg A: Statins for all patients with type 2 diabetes: not so soon. Lancet 2004, 364:64I-642.

61. Coulhon HM, Betteridge DJ, Durrington PN, et al:: Primanry prevention of cardiovascular disease with atorvastatin in type 2 diabetes in the Collaborative Atorvastatin Diabetes Study (CARDS): multicenter randomised placebo-controlled trial. Lancet 2004, 364:685-696.

62. Inoue E, Takashashi F, Katayama S, et al.: Improvement of glucose tolerance by bezafibrate in non-obese patients with hyperlipidemia and impaired glucose tolerance. Diabetes Res Clin Pract 1994, 25:199-205.

63. Shepherd J, Cobbe SM, Ford I, et al:: The West of Scotland Coronary Prevention Program: design and methods for clinical trial in the prevention of type 2 diabetes. Diabetes care 1998 22:623-624.

64. Mykkhanen L, Kuusisto J, Pyorala K, et al.: Increased risk of noninsulin dependent diabetes mellitus in elderly hypertensive subjects. J Hypertens 1994, I 2: | 425- I 432.

65. Gress TW, Nieto FJ, Shahar G, et al.: Hypertension and antihypertensive therapy as risk factors for type 2 diabetes mellitus. Atherosclerosis Risk in Communities study. N Engl J Med 2000, 342:905-912.

66. Jackson EK: Diuretics. In The Pharmacological Basis of Therapeutics Edited by: Hardman JG, Limbird LE, Gilman AG. Mc Graw Hill, New York; 2001:757-788.

67. Baba T, Kodama T, Yajima $T$, et al.: Effects of pravastatin, a 3 hydroxy-3-methyl glutaryl co-enzyme reductase inhibitor, on glucose tolerance in patients with essential hypertension. Diabetes Care 1993, 16:402-404.

68. Mahley RW, Bersot TP: Drug therapy for hypercholesterolemia and dyslipidemia. In The Pharmacological Basis of Therapeutics Edited by: Hardman JG, Limbird LE, Gilman AG. McGraw Hill, New York; 2001:971-1002.

69. Jick SS, Bradbury BD: Statins and newly diagnosed diabetes. $\mathrm{Br}$ Clin Pharmacol 2004, 58:303-309.

70. Esmann $\mathrm{V}$, Lundbaek K, Madsen PH: Types of exudates in diabetic retinopathy. Acta Medica Scandinavica 1963, 174:375-384.

71. Brown GC, Ridley M, Haas D, et al.: Lipaemic diabetic retinopathy. Ophthalmology 1984, 9 I: | 1490-1495.

72. Dodson PM, Gibson JM: Long term follow-up of and underlying medical conditions in patients with diabetic exuadative maculopathy. Eye 1991, 5:699-703.
73. Miccoli R, Odello G, Giampietro O, et al:: Circulating lipid levels and severity of diabetic retinopathy in type $I$ diabetes mellitus. Ophthalmic Res 1987, 19:52-56.

74. Mohan R, Mohan V, Susheela L, et al: Increased LDL cholesterol in non-insulin dependent diabetics with maculopathy. Acta Diabetol Lat 1984, $21: 85-89$.

75. Hall NF, Gale CR, Sydall H, et al.: Risk of macular degeneration in users of statins: cross sectional study. BMJ 200I, 323:375-376

76. Gordon B, Chang S, Kavanagh M, et al.: The effect of lipid lowering on diabetic retinopathy. Am J Ophthalmol I99|, I I 2:385-389.

77. Dale J, Farmer J, Jones AF, Gibson JM, Dodson PM: Diabetic ischaemic and exudative maculopathy: are their risk factors different? Diab Med 2000, I7:47.

78. Sen K, Misra A, Kumar A, et al.: Simvastatin retards progression of retinopathy in diabetic patients with hypercholesterolemia. Diabetes Res Clin Pract 2002, 56: I- I I.

79. Kinlay S, Pluzky J: Effects of lipid-lowering therapy on vascular endothelial function. Curr Cardiol Rep 1999, I:238-243.

80. Vasa M, Fichtlscherer S, Adler K, et al.: Increase in circulating progenitor cells by statin therapy inpatients with stable coronary artery disease. Circulation 200I, 103:2885-2890.

8I. Ganne F, Vasse M, Beaudeux JL, et al.: Cerivastatin, an inhibitor of HMG-CoA reductase, inhibits urokinase/urokinase-receptor expression and MMP, a secretion by peripheral blo0d monocytes-a possible protective mechanism against atherothrombosis. Thromb Haemost 2000, 84:680-688.

82. Blockenhorn DH, Azen SP, Crawford DN, et al:: Effects of colestipol-niacin therapy on human femoral atherosclerosis. Circulation 1991, 81 : 438-447.

83. Bauchwald H, Varco RL, Matts JP, et al: Effect of partial ilea bypass on mortality from coronary heart disease in patients with hypercholesterolemia. Report of the Program on Surgical Control for Hyperlipedemas (POSCH). N Engl J Med I990, 323:946-955

84. Pederson TR, Kjekshus J, Pyorala K, et al.: Effect of simvastatin of ischemic signs and symptoms in the Scandinavian Simvastatin Study (4S). Am J Cardiol 1998, 81:333-335.

85. Mondillo S, Ballo P, Barbati R, et al.: Effect of simvastatin on walking performance and symptoms of intermittent claudication in hypercholestecolemic patients with peripheral vascular disease. Am J Med 2003, I I 4:359-364.

86. Mohler ER III, Hiatt WR, Creager MA: Cholesterol reduction with atorvastatin improves walking distance inpatients with peripheral arterial disease. Circulation 2003, 108: 148I-1488.

87. Aronow WS, Nayak D, Woodworth S, et al.: Effect of simvastatin versus placebo on treadmill exercise time until the onset of intermittent claudication in older patients with peripheral arterial disease at six months and at one year after treatment. Am J Cardiol 2003, 92:7। I-7II2.

88. Stanislaus R, Singh AK, Singh I: Lovastatin treatment decreases mononuclear cell infiltration into the CNS of lewis rats with experimental allergic encephalomyelitis. J Neurosci Res 200I, 66:155-162.

89. Shields D, Avgeropoulos NG, Banik NL, et al.: Active multiple sclerosis charecterised by extensive mononuclear phagocyte infiltration. Neurosci Res 2000, 25:1517-1520.

90. Youssef S, Sture O, Patarroyo JC, et al.: The HMG CoA reductase inhibitor atorvastatin, promotes a Th2 bias and reverses paralysis in central nervous system autoimmune disease. Nature 2002, 420:78-84.

91. Baker D, Adamoon P, Greenwood S: Potential of statins for the treatment of multiple sclerosis. Lancet Neurol 2003, 2:9-10.

92. Vollmer T, Key L, Durkaisiki $\mathrm{V}$, et al: Oral simvastatin treatment in rlapsing-remitting multiple sclerosis. Lancet 2004, 363:16-7.

93. Prospective Studies Collaboration. Cholesterol, diastolic blood pressure and stroke: 13,000 strokes in $4,50,000$ people in 45 prospective cohorts. Lancet 1995, 346:1647-1653.

94. Corvol JC, Bouzomondo A, Sirol M, et al.: Differential effects of lipid lowering therapies in stroke prevention. Arch Intern Med 2003, 163:669-674.

95. Law MR, Wald NJ, Rudnicka AR: Quantifying effect of statins on low density lipoprotein cholesterol, Ischemic heart disease and stroke: systematic review and meta-analysis. BMJ 2003, 326: $1423-1428$. 
96. Cheung BM, Lauder J, Lau P, et al.: Meta-analysis of large randomised controlled trials to evaluate the impact of statins on cardiovascular outcomes. Br J Clin Pharmacol 2003, 57:640-65 I.

97. Frears ER, Stephens DJ, Walters CE, et al.: The role of cholesterol in the biosynthesis of beta-amyloid. Neuroreport 1999, I 0:1699-1705

98. Sparks DL, Martin TA, Gross DR, et al.: Link between heart diseases, cholesterol and Alzheimer's disease: a review. Micros Res Tech 2000, 50:287-290.

99. Wolozin B, Kellman W, Ruossean P, et al.: Decreased prevalence of Alzheimer disease associated with 3-hydroxy-3-methylglutaryl coenzyme and reductase inhibitors. Arch Neurol 2000, 57:|439-|443.

100. Jick H, Zornberg GL, Jick SS, et al.: Statins and risk of dementia. Lancet 2000, 356:1627-1631.

I0I. Scott HD, Laake K: Statins for the reduction of risk of Alzheimer's disease. Cochrane Database Syst Rev 2001:CD003160.

102. Simons M, Schwarzler F, Lutjohann D, et al.: Treatment with simvastatin in normocholesterolemic patients with Alzheimer's disease. A 26-week randomised, placebo-controlled, doubleblind trial. Ann Neurol 2002, 52:346-350.

103. Casserley I, Topol E: Convergence of atherosclerosis and Alzheimer's disease: inflammation, cholesterol and misfolded proteins. Lancet 2004, 363: | |39- I | 46.

104. Eckert GP, Cairns NS, Maras A, et al.: Cholesterol modulates the membrane-disordering effects of B-amyloid peptides in the hippocampus: specific changes in Alzheimer's disease. Demen Geriatr Cogn Disord 2000, I I: | 81 - | 86.

105. Swan GE, Lahue A, Carmelli O, Reed TE, Fabritz RR: Decline on cognitive performance in aging twins: heritability and biobehavioral predictors from the National Heart, Lung and Blood Institute Twin Study. Arch Neurol 1992, 49:476-48I.

106. Kuisisto J, Koivisto K, Mykkanen L, et al.: Association between features of the insulin resistance syndrome and Alzheimer's disease independently of apolipoprotein E4 phenotype: cross population based study. BMJ 1999, 3 1 5: 1045-1049.

107. Young-Xu Y, Chan KA, Uao JK, et al.: Long term statins use and psychological well being. J Am Coll Cardiol 2003, 42:690-697.

108. Yang C-C, Jick SS, Jick M: Lipid lowering drugs and the risk of depression in suicidal behavior. Arch Intern Med 2003, 163:1926-1932.

109. Zureik M, Courbon D, Ducemethere P: Serum cholesterol concentration and death from suicide in man: Paris Prospective Study. BMJ 1996, 3 I 3:649-657.

I I0. Streegmans $\mathrm{PH}$, Fekkes $\mathrm{O}$, Hoes $\mathrm{AW}$, et al: Low serum cholesterol concentration and serotonin metabolism in men. $B M$ |996, 3 1 2:221

III. Gallerani M, Manfredini R, Carassiolo S, et al.: Serum cholesterol concentrations in parasuicide. BMJ 1995, 310:1632-1636.

I 12. Ryman A: Cholesterol, violent death and mental disorder. $B M]$ 1994, 309:421-422.

I13. Steegmans PH, Hoes AW, Bak AA, et al:: Higher prevalence of depressive symptoms in middle aged men with low serum cholesterol levels. Psychosom Med 2000, 62:205-2I I

I 14. Lines C: Hazards of reducing cholesterol. BMJ 1994, 309:54I.

I 15. Downs JR, Oster G, Santanello NC: HMG CoA reductase inhibitors and quality of life. JAMA 1993, 269:3109-3108.

1 16. Wardle J, Armitage J, Collins R, et al.: Randomized placebo controlled trial of effect on mood of lowering cholesterol concentration. BMJ 1996, 3 I3:715-7/8.

I 17. Weitz-Schmidt G, Welzenbach F, Brinkmann V, et al.: Statins selectively inhibit leukocyte function antigen-I by binding to a novel regulatory functions. Nat Med 200I, 7:687-692.

1 18. Leung BP, Sattar N, Criily A, et al.: A novel anti-inflammatory role for simvastatin in inflammatory arthritis. J Immunol 2003 I 70: 1524-1530

119. Abud-Mendoza C, de la Fuente H, Cuevas Orta E, et al.: Therapy with statins in patients with refractory rheumatic diseases: a preliminary study. Lupus 2003, I 2:607-6II

120. McCarrey DW, Mclnnes IB, Madhok R, et al.: Trial of atorvastatin in Rheumatoid Arthritis (TARA), double-blind, randomised, placebo-controlled trial. Lancet 2004, 363:20I5-202I.

121. Mundy G, Garett R, Harris S, et al.: Stimulation of bone formation in vitro and in rodents by statins. Science 1999, 286: $1946-1949$
122. Sakou T: Bone morphogenetic proteins: from basic studies to clinical approaches. Bone 1998, 22:591-603.

123. Baver DC, Mundy G, Jamal S, et al.: Statin use, bone mass and fracture an analysis of two prospective studies (abstract). J Bone Mines Res 1999:I I88.

124. Wang PS, Solomon DH, Mogun H, et al.: HMG-CoA reductase inhibitors and the risk of hip fractures in elderly patients. JAMA 2000, 283:321I-3216.

125. Chan KA, Andrade SE, Boles M, et al.: Inhibitors of hydroxymethyl glutaryl coenzyme reductase and risk of fractures among older women. Lancet 2000, 355:2185-55

126. Meier CR, Senlienger RG, Kraenzlin ME, et al.: HMG-CoA reductase inhibitors and the risk of fractures. JAMA 2000, 283:3205-3210

127. La Croix AZ, Cauley J, Pettinger M: Statin use, clinical fracture and bone density in post-menopausal women: results from the Women's Health Initiative Observational Study. Ann Intern Med 2003, I39:97-104.

128. VanStaa TP, Wegman S, de Vries F, et al.: Use of statins and risk of fractures. JAMA 200I, 286:669-670.

129. Cosman F, Nieves J, Zion M, et al.: Effects of short-term cerivastatin on bone tumour. Program and abstracts from the Twenty Third Annual Meeting of the American Society of Bone \& Mineral Research, October I2-16, 200I; Phoenix, Arizona Abstract SA4I5. J Bone Miner Res 200I, PI6(Suppl I):529.

130. Chan $M H$, Mak TW, Chiu RW, et al.: Simvastatin increases serum osteocalcin concentration in patients treated for hypercholesterolemia. / Clin Endocrinol Met 200I, 86:4556-4559.

13I. Stein PA, Farnier M, Waldstreicher J, et al.: Effects of statins on bio-markers of bone metabolism. A randomised trial. Nutr Metab Cardiovasc Dis 200 I, I I:84-87.

132. Watanabe S, Fukomoto S, Takeuchi Y, et al.: Effects of I-year treatment with fluvastatin or pravastatin on bone. Am J Med 200I, I 1 0:584-587

133. Gutierrez G, Garrett Rossinni G, et al:: Dermal application of lovastatin for 5 days stimulates bone formation or ovanectomiced rats by I00\%. J Bone Miner Res 200 I, I 6(SuppI I):S222.

134. Buchward $\mathrm{H}$ : Cholesterol inhibition, cancer and chemotherapy. Lancet 1992, 339: I I54.

135. Cauley JA, Zmuda JM, Lui LY, et al.: Lipid-lowering drug use and breast cancer in older women: a prospective study. J Women Health 2003, I 2:749-756.

136. Hebert PR, Gaziao M, Chan GS, et al.: Cholesterol lowering with statin drugs: risk of stroke and total mortality: an overview of randomised trials. JAMA 1997, 278:313-32I.

137. Jacobe $D$, Blackburn $H$, Higgens $M$, et al.: Report of the conference in low blood cholesterol: mortality associations. Circulation 1992, 86: 1046-1060.

138. Davey-Smith G, Pekkanen J: Should there be a moratarium on the use of cholesterol lowering drugs? BM] I992, 304:43 I-434.

139. Newman TB, Hulley SB: Carcinogenicity of lipid lowering drugs. JAMA 1996, 275:55-60.

140. Mauss S: HIV associated and antiretroviral induced hyperlipidemia an update. J HIV Ther 2003, 8:29-3I.

14I. Penzak SR, Chuck SK, Stajich GV: Safety and efficacy of HMGCoA reductase inhibitors for treatment of hyperlipidemia in patients with HIV infection. Pharmcotherapy 2000, 20:1066-1071.

142. Stein JH, Marwood MA, Ballehumeur JL, et al.: Effects of pravastatin on lipoproteins and endothelial function in patients receiving human immunodeficiency virus protease inhibitors. Am Heart J 2004, I47:EI8.

143. Bonnet F, Balestre E, Thiebaut R, et al.: Groups D' Epidemiologie chanque due SIDA en Aquitarne (GECSA). Fibrates or statins and lipid plasma levels in $\mathbf{2 4 5}$ patients treated with highly active antiretroviral therapy. Aquitaine Cohort, France, 1999-200 I. HIV Med 2004, 5:133-139.

144. Maziere JC, Landureau JC, Giral P, et al.: Lovastatin inhibits HIV-I expression in $\mathrm{H} 9$ human $\mathrm{T}$ lymphocytes cultured in cholesterol-poor median. Biomed Pharmacother 1994, 48:367. Abstract

145. Del Real G, Jimenez-Baranda S, Mira E, et al.: Statins inhibit HIV-2 infection by downregulating Rho activity. J Exp Med 2004, 54:54I-547.

146. de Denus S, Jazairi A, Loh E, et al.: Dyslipidemias and HMG-CoA reductase inhibitors prescription in heart transplant recipients. Ann Pharmacother 2004, 38: |36-|4|. 
147. Mahes AS, Dave N, Knipp GT, Friedman GS: Drug related dyslipidemia after renal transplantation. Am J Health Syst Pharm 2004, 61:565-585.

148. Kobashigawa SA: Statins in solid organ trnasplantation. Is there an immunosuppressive effect? Am J Transplant 2004, 4:1013-1018.

149. Ohno T, Shigetoms M, Ihara K, et al.: Skeletal reconstruction by vascularised allogenic bone transplantation: effects of statins in rats. Transplantation 2003, 76:869-87I.

150. Solovey A, Kollander R, Shet A, et al.: Endothelial cell expression of tissue factor in sickle mice is augmented by hypoxia/reoxygenation and inhibited by lovastatin. Blood 2004, 104:840-846.

15I. Weatherall DJ: Pharmacological treatment of monogenic disease. Pharmacogenomics J 2003, 3:264-266.

152. Tan A, Levasay M, Dahm C, et al.: Lovastatin induces fibroblast apoptosis in vitro and in vivo. A possible therapy for fibroproliferative disorder. Am \& Respir Crit Care Med 1999, 1 59:220-227.

153. Nadrous HF, Ryx JH, Douglas WW, et al:: Impact of angiotensin converting enzyme inhibitors and statins in survival in idiopathic pulmonary fibrosis. Chest 2004, 1 26:438-446.

154. Jung KH, Chu K, Jeong SW, et al.: HMG CoA reductase inhibitor, atorvastatin, promotes sensorimotor recovery, suppressing acute inflammatory reaction after experimental intracerebral hemorrhage. Stroke 2004, 35: 1744- 1749.

155. Almong $Y$, Shefer A, Novack V, et al.: Prior statin therapy is associated with a decreased rate of severe sepsis. Circulation 2004, I 1 0:880-885.

156. Durant R, Klouche K, Delbosc $S$, et al:: Superoxide anion overproduction in sepsis: effects of Vitamin $E$ and simvastatin. Shock 2004, 22:34-39.

157. Almong Y: Statins, inflammation and sepsis hypothesis. Chest 2003, I 24:740-743.

158. Blume C, Sabuda-Widermann D, Pfeilsschiffer J, et al:: Cerivastatin inhibits proliferation of interleukin-I beta induced rat mesangial cells by enhanced formation of nitric oxide. Eur J Pharmacol 2004, 485: I- 10 .

159. Ravnskov U, Rosch PJ, Langsjoen PH, et al.: Evidence from the simvastatin trials that cancers is a probable long-term side effect. Unpublished letter to The Lancet .

160. Ravnskov U: Statins increase the risk of cancer among the elderly. Lalkartidningen 2003, 100:974.

161. Backes JM, Howard PA: Association of HMG-CoA reductase inhibitors with neuropathy. Pharmacother 2003, 37:274-278.

162. Gaist D, Gareia Rodriguez LA, Heurta C, et al:: Are users of lipidlowering drugs at increased risk of peripheral neuropathy? Eur J Clin Pharmacol 2001, 56:931-933.

163. Golomb BA, Kane T, Dimsdale JE: Severe irritability associated with statin cholesterol-lowering drugs. Quart JM 2004, 97:229-235.

164. Golomb BA: Statin adverse effects. Geriatric Times 2004, 5:

165. Wagstaff LR, Mitton MW, Arvik BM, et al.: Statin-associated memory loss: analysis of 60 case reports and review of the literature. Pharmaotherpy 2003, 23:87I-880.

166. Edison RJ, Muenk E: Central nervous system and limb anomalies in case reports of first-trimester statin exposure. $N \mathrm{EnglJ}$ Med 2004:125-127.

167. Kendrick M: We are sleep-walking into what could become a major medical disaster because statin drugs will soon be sold over-the-counter. Red Flags Daily . June 17,2004

168. de Graaf $L$, Brouwers AHPM, Diemont WL: Is decresed libido associated with the use of HMG-Co A- reductase inhibitors? Br J Cl Pharmacol 2004, 58:326-328.

169. Fonarow GC, Gawlinski A, Moughrabi S, et al:: Improved treatment of coronary heart disease by implementation of a Cardiac Hospitalization Atherosclerosis Management Program (CHAMP). Am J Cardiol 2001, 87:819-822.

170. Chandra KK, Malhotra S, Gupta M, et al:: Changing trends in the hospital management of unstable angina: a drug utilization analysis. Int / Clin Pharmacol Ther 2004, 42:575-578.

171. Mitchell JA, Warner TD: Cyclo-oxygenase-2: pharmacology, physiology, biochemistry and relevance to NSAID therapy. $\mathrm{Br}$ J Cl Pharmacol 1999, I 28: I I 21-I I 32.

172. Seibert K, Zhang Y, Leahyo K, et al.: Distribution of COX-I and COX-2 in normal and inflamed tissues. Adv Exp Med Biol 400A: $167-170$.
173. Pandhi P, Shafiq N, Malhotra S: Abstracted. Gastrointestinal toxicity of cyclogenase-2 inhibitors: an experimental study. In Presented at the XXV th World Congress of Pharmacology San Fransisco, USA. 2002, July 7-12

174. Malhotra S, Shafiq N, Pandi P: A CLASS Act or just VIGORously promoted. [http://www.medscape.com/viewarticle/470342]. Accessed: 30.11 .2004

175. Chow JC, Higgins MJ, Rudney H: The inhibitory effect of statins on HMG Co A reductase. Biochem Biophys Res Commun 1975, 63:1077-1084.

176. Waters D, Higginson L, Gladstone P: Effect of monotherapy with an HMG Co A reductase inhibitor on the progression of coronary atherosclerosis as assessed by serial quantitative arteriography: the Canadian Coronary Atherosclerosis Intervention Trial. Circulation 1994, 89:959-968.
Publish with Biomed Central and every scientist can read your work free of charge

"BioMed Central will be the most significant development for disseminating the results of biomedical research in our lifetime. "

Sir Paul Nurse, Cancer Research UK

Your research papers will be:

- available free of charge to the entire biomedical community

- peer reviewed and published immediately upon acceptance

- cited in PubMed and archived on PubMed Central

- yours - you keep the copyright
BioMedcentral 